\title{
El inminente tránsito hacia una ciudadanía supranacional de la Unión Europea*
}

\author{
Sergio Alonso de León \\ Letrado de la Comunidad de Madrid
}

\begin{abstract}
Sumario: I. Introducción. - II. Hacia la desaparición de la noción de las situaciones puramente internas. 1. La herencia de la jurisprudencia clásica de las libertades comunitarias. 2. La evolución jurisprudencial sobre la noción de las situaciones puramente internas. 3. La paradoja de la discriminación inversa. - III. La ciudadanía de la Unión llamada a ser un estatuto fundamental. 1. El tradicional enfoque por categorías y los condicionantes económicos. 2. El estatuto fundamental de la ciudadanía de la Unión. - IV. El nacimiento de derechos políticos supranacionales. 1. Los derechos de sufragio activo y pasivo: derechos puramente transnacionales. 2. Los derechos de petición, de recurrir al Defensor de Pueblo y de dirigirse a las Instituciones: derechos no exclusivos de los ciudadanos. 3. La iniciativa ciudadana europea. $-\mathrm{V}$. Ciudadanía de la Unión y nacionalidad de los Estados miembros: ¿relación en una sola dirección? 1. El derecho de la nacionalidad: competencia soberana de los Estados miembros. 2. El Derecho de la nacionalidad debe encuadrarse en el Derecho de la Unión. VI. Conclusiones.
\end{abstract}

Resumen: La ciudadanía de la Unión Europea ha sido hasta la fecha una ciudadanía transnacional. Los derechos que confería quedaban condicionados a un elemento transfronterizo para no quedar relegados a una situación puramente interna, y se sometían a condicionantes de tipo económico. Los derechos políticos tenían una dimensión también eminentemente transnacional. Por otro lado, la nacionalidad de los Estados miembros habría actuado como requisito para la ciudadanía de la Unión, pero sin que ésta pudiera influir en aquella.

La jurisprudencia del Tribunal de Justicia de la Unión Europea, en pronunciamientos recientes, ha producido una cierta alteración en este punto de partida, sentando las bases para una inminente transformación de la ciudadanía de la Unión en ciudadanía supranacional. Este estudio pretende analizar las claves de este tránsito.

Palabras clave: ciudadanía de la Unión Europea, situación puramente interna, iniciativa ciudadana europea, libre circulación de personas, nacionalidad.

Abstract: EU citizenship has been a transnational citizenship so far. The rights conferred by it were conditional to a cross-border element. Otherwise, they were

* Recibido el 8 de marzo de 2012, aceptado el 11 de abril de 2012. 
to be relegated to a purely internal situation. They were subject to economic conditions too. Political rights also had a predominantly transnational nature. On the other hand, nationality of Member States was a requirement for EU citizenship, but the latter could not affect the former.

In recent rulings, the Court of Justice of the European Union has brought some changes in this respect, setting the stage for an imminent transformation of EU citizenship into supranational citizenship. This paper aims at analyzing the key elements of this transition.

Keywords: EU citizenship, purely internal situation, European Citizens' Initiative, Free Movement of Persons, Nationality.

\section{Introducción}

La ciudadanía de la Unión Europea solemnemente proclamada en el Tratado de Maastricht constituye un concepto jurídico que no ha desarrollado hasta ahora todo su potencial. Considerada un estatuto subordinado a la nacionalidad de los Estados miembros, había quedado inicialmente limitada a un catálogo de derechos, de los que la piedra angular la constituía la transformación de la libre circulación de trabajadores en la libre circulación de personas.

La ciudadanía de la Unión nace y se desarrolla como una ciudadanía transnacional, en el sentido de que sólo cobra significado cuando el nacional de un Estado miembro se desplaza o reside en otro Estado miembro. Ni siquiera parece posible que esa ciudadanía se traduzca inicialmente en una plena libre circulación de personas. La distinción por categorías - trabajador, estudiante, desempleado, etc. - característica del periodo previo a la ciudadanía no se supera totalmente ni siquiera por la Directiva 2004/38, de libre circulación y residencia de los ciudadanos de la Unión. Tampoco las consideraciones económicas que se pretendían superar se pueden dejar totalmente al margen, salvo que se acceda a la condición de residente permanente.

Mientras tanto, el Derecho de la nacionalidad, a la que la ciudadanía se subordina, quedaba aparentemente salvaguardado de las intromisiones que la ciudadanía de la Unión pudiera intentar en lo que se consideraba una de las prerrogativas esenciales de los Estados. La relación nacionalidad-ciudadanía, según la construcción de los Tratados, debía ser unidireccional.

El paso esencial para la ciudadanía de la Unión consiste en avanzar desde la tradicional libre circulación y residencia, interpretada bajo el principio de no discriminación y acompañada de algunos otros derechos políticos transnacionales, a una ciudadanía verdaderamente supranacional, cuyo 
ejercicio corresponda también a los ciudadanos que no cruzan las fronteras y cuya relación con la nacionalidad vaya más allá de la subordinación.

¿Este paso se está dando? No puede afirmarse con rotundidad, pero la jurisprudencia más reciente del Tribunal de Justicia de la Unión Europea, unida a alguna novedad introducida por el Tratado de Lisboa y sólo recientemente implementada, sí nos permite argumentar que esta puerta se está abriendo tímidamente. Nos hallamos ante un momento de transformación de la ciudadanía de la Unión que, veremos, comienza a tomar unas características supranacionales.

Existen varios aspectos en que se manifiesta dicho tránsito. Los analizamos uno por uno a continuación.

\section{Hacia la desaparición de la noción de las situaciones puramente internas}

\section{La herencia de la jurisprudencia clásica de las libertades comunitarias}

Uno de los límites más importantes que tradicionalmente impone la jurisprudencia del Tribunal de Justicia sobre las libertades de circulación del Mercado Interior lo constituye la noción de la situación puramente interna. Ello es aplicable a todas las libertades comunitarias, no sólo a la libre circulación de personas. Si no existe una situación transfronteriza, entonces no hay relevancia para el Mercado Interior, no hay conexión con el Derecho de la Unión Europea.

Esta noción constituye una de las piezas más importantes sobre las que la jurisprudencia del Tribunal de Justicia ha construido la difícil respuesta a la casi eterna cuestión del equilibrio entre las competencias comunitarias y la soberanía nacional ${ }^{1}$.

Respecto a todas las libertades de circulación, esta noción ha ido estrechándose en la jurisprudencia del Tribunal de Justicia, de forma pendulante pero progresiva. En el caso de la libre circulación de personas, este estrechamiento ha tenido unos caracteres especiales, ya que ha venido acompañado de una importancia progresiva del concepto de ciudadanía, que se ha venido plasmando de forma cada vez más decidida en los pronunciamientos del Tribunal.

Conviene por tanto analizar la evolución que se ha producido en la jurisprudencia europea.

${ }^{1}$ MARZO, C., «La definition d'une nouvelle méthode de jugement attachée à la citoyenneté européenne: réflexions autour de l'arrêt Förster», en Revue trimestrelle de droit européen, 45(3), 2009, p. 439. 


\section{La evolución jurisprudencial sobre la noción de las situaciones puramente internas}

El punto de partida para la libre circulación, entonces de los trabajadores, es que las situaciones internas, relativas a nacionales de un Estado miembro y que despliegan sus efectos en el propio Estado miembro no son competencia del Tribunal de Justicia, pues que no hay vínculo suficiente con el Derecho comunitario, y por tanto son inadmisibles.

Esta idea aparece con claridad en el asunto Saunders ${ }^{2}$ que concierne a ciudadano británico que alega un obstáculo a su libre circulación en el Reino Unido. El Tribunal de Justicia razona del siguiente modo:

«... las disposiciones del Tratado en materia de libre circulación de los trabajadores no pueden aplicarse a situaciones puramente internas de un Estado miembro, es decir, cuando no exista ningún punto de conexión con alguna de las situaciones que contempla el Derecho comunitario.» ${ }^{3}$

Esta jurisprudencia inicial se mantiene en este primer momento y se reproduce en otros asuntos. Es paradigmático el asunto Iorio $^{4}$ que se refiere a un abogado italiano que solicita ejercer libremente su profesión en todo el territorio italiano y cuyos argumentos, aunque rechazados por el Tribunal de Justicia son visionarios de la restricción posterior a la noción de situación interna.

Esta jurisprudencia se reitera en varias ocasiones ${ }^{5}$. Lo que nos interesa es que incluso con posterioridad a la entrada en vigor de las disposiciones del Derecho originario relativas a la ciudadanía, el Tribunal de Justicia no revisaría de raíz esta limitación constituida por la noción de situación puramente interna. Así lo afirma con rotundidad en el asunto Uecker y Jacquet ${ }^{6}$ :

«...procede señalar que la ciudadanía de la Unión, prevista en el artículo 8 del Tratado CE, no tiene por objeto extender el ámbito de aplicación material del Tratado también a situaciones internas que no tienen

2 Asunto 175/78, The Queen contra Vera Ann Saunders, Sentencia del Tribunal de Justicia de 28 de marzo de 1979, Rec. 1979, p. 01129 (Edición especial española p. 00683).

3 Ibid., apartado 11.

${ }^{4}$ Asunto 298/84, Paolo Iorio contra Azienda autonoma delle ferrovie dello Stato, Sentencia del Tribunal de Justicia de 23 de enero de 1986, Rec. 1986, p. 00247.

5 Asunto 180/83, Moser, Sentencia del Tribunal de Justicia de 28 de junio de 1984, Rec. 1984, p. 2539, apartado 15; asunto C-332/90, Steen, Sentencia del Tribunal de Justicia de 28 de enero de 1992, Rec. 1992, p. I-341, apartado 9; y Asunto C-19/92, Kraus, Sentencia del Tribunal de Justicia de 31 de marzo de 1993, Rec. 1993, p. 1-1663, apartado 15.

${ }^{6}$ Asuntos acumulados C64/96 y C-65/96, Kari Uecker y Vera Jacquet contra Land Nordrhein-Westfalen, asuntos acumulados C64/96 y C-65/96, Sentencia del Tribunal de Justicia de 5 de Junio de 1997, Rec. 1997, p. I-03171. 
ningún vínculo con el Derecho comunitario. [...] Las posibles discriminaciones de que pueden ser objeto los nacionales de un Estado miembro en lo que respecta al Derecho de ese Estado están comprendidas en el ámbito de aplicación de éste, por lo que deben ser resueltas en el marco del sistema jurídico interno de dicho Estado.» ${ }^{7}$

Esta posición originaria tardaría poco en ser matizada progresivamente. En los casos en que había una previa circulación transfronteriza, el retorno al Estado miembro de la nacionalidad podía entrañar un obstáculo a la libre circulación a ser valorado por el Tribunal de Justicia. Así resulta en particular del asunto Singh ${ }^{8}$. Este asunto se origina por una denegación a la prolongación de un permiso de residencia del que disfrutaba el marido, nacional de un tercer Estado, de una ciudadana británica que habían residido en Alemania y deseaban regresar al Reino Unido. No había ya situación puramente interna en la medida en que, según el razonamiento del Tribunal, el resultado de la libre circulación era perjudicial para quien lo había ejercido. En particular, es revelador el siguiente considerando:

«Podría disuadirse a un nacional de un Estado miembro de abandonar su país de origen para ejercer una actividad por cuenta ajena o por cuenta propia, a efectos del Tratado, en el territorio de otro Estado miembro, si no pudiera gozar, al regresar al Estado miembro de su nacionalidad para ejercer una actividad por cuenta ajena o por cuenta propia, de facilidades de entrada y de residencia cuando menos equivalentes a aquellas de las que puede disponer, conforme al Tratado o al Derecho privado, en el territorio de otro Estado miembro.» ${ }^{9}$

Esta jurisprudencia se afianza después en un caso que concierne a nuestro país. En el asunto Fernández de Bobadilla ${ }^{10}$, el Tribunal considera que a una persona que ha obtenido una cualificación profesional en un Estado miembro no se le puede obviar este mérito para unas oposiciones cuando sí se habría tenido en cuenta de haberse obtenido en España. Debe existir una equiparación al migrante respecto del nacional que retorna. En concreto, dice el Tribunal de Justicia:

«el asunto objeto del procedimiento principal se refiere a una persona de nacionalidad española que desea ejercer su profesión en España. No

7 Ibid., apartado 23.

8 Asunto C-370/90, The Queen contra Surinder Singh, Sentencia del Tribunal de Justicia de 7 de julio de 1992, Rec. 1992, p. I-04265.

9 Ibid., apartado 19.

10 Asunto C-234/97, Teresa Fernández de Bobadilla contra Museo Nacional del Prado, Sentencia del Tribunal de Justicia de 8 de julio de 1999, Rec. 1999, p. I-04773. 
obstante, si un nacional de un Estado miembro, por el hecho de haber residido habitualmente en el territorio de otro Estado miembro y de haber adquirido en él una capacitación profesional, se encuentra, respecto del Estado miembro del que es originario, en una situación equiparable a la de un trabajador migrante, deberá también disfrutar de los derechos y de las libertades que confiere el Tratado.» ${ }^{11}$

El carácter transfronterizo de la situación va tomando progresivamente unos contornos más difuminados. Si bien existió circulación en los asuntos que hemos expuesto, en el conocido asunto Bosman ${ }^{12}$ no ha habido aún un movimiento transfronterizo de la persona, pero aun así se valora que existe obstáculo para esa circulación sobre la que hay certeza de que se va a producir. El razonamiento del Tribunal es el siguiente:

«... de las apreciaciones sobre los hechos efectuadas por el órgano jurisdiccional de remisión, resulta que el Sr. Bosman había celebrado un contrato de trabajo con un club de otro Estado miembro para ejercer un empleo por cuenta ajena en el territorio de dicho Estado. Como señaló acertadamente el interesado, al hacerlo, respondió a una oferta efectiva de trabajo en el sentido de la letra a) del apartado 3 del artículo 48.»13

En esta evolución, el asunto García Avello ${ }^{14}$ supone un salto importante. Este asunto versa sobre la fijación de los apellidos de los hijos de un matrimonio hispano-belga, residentes en Bélgica y con doble nacionalidad. Bélgica no admite su inscripción con el apellido registrado conforme a las normas españolas, ya que, se mantiene, a estos efectos los menores son considerados belgas residentes en su país. Pues bien, aún en este caso, sin que haya habido circulación ni es previsible que la haya, el Tribunal de Justicia admite que no es una situación puramente interna en atención a la doble nacionalidad que no puede ser ignorada, y justifica el vínculo con el Derecho de la Unión:

«...existe dicho vínculo con el Derecho comunitario en relación con las personas [...], que son nacionales de un Estado miembro que residen legalmente en el territorio de otro Estado miembro.

Frente a esta conclusión no cabe oponer la circunstancia de que los interesados en el procedimiento principal también tienen la nacionalidad

11 Ibid., apartado 30.

12 Asunto C-415/93, ASBL, Royal club liégeois SA y UEFA contra Jean-Marc Bosman, Sentencia del Tribunal de Justicia de 15 de diciembre de 1995, Rec. 1995, p. I-04921.

13 Ibid., apartado 90.

${ }^{14}$ Asunto C-148/02, Carlos Garcia Avello contra Bélgica, Sentencia del Tribunal de Justicia de 2 de octubre de 2003, Rec. 2003, p. I-11613. 
del Estado miembro en que residen desde su nacimiento y que, según las autoridades de dicho Estado, por ello es la única que éste reconoce.» ${ }^{15}$

Ahora bien, implícitamente se reconoce que el vínculo existe también en la medida en que la situación puede, aún hipotéticamente, perjudicar a la libre circulación de los menores y dar lugar a confusión sobre su identidad en otros países como, en particular, en España. Este argumento fue construido con detalle en las conclusiones del Abogado General Jacobs ${ }^{16}$.

En realidad, el Tribunal de Justicia clarifica en el asunto, de antecedentes fácticos similares, Grunkin y Paul $^{17}$ que esta disparidad de apellidos puede causar graves inconvenientes para los interesados, derivados de las dificultades para disfrutar en un Estado miembro cuya nacionalidad poseen de los efectos jurídicos de actos o documentos expedidos con un apellido reconocido en otro Estado miembro cuya nacionalidad también posee. Por tanto, se está razonando aquí sobre la base de una libre circulación hipotética o «ficticia» ${ }^{18}$.

Ello nos lleva al último estadio de la jurisprudencia del Tribunal de Justicia, que ha llegado más lejos que en los asuntos anteriores al considerar que el carácter transfronterizo no sólo puede ser futuro, sino también puramente potencial o hipotético. Este es el hito que supone el asunto Ruiz Zambrano $^{19}$.

En este caso lo que resulta controvertido es la orden de expulsión de Bélgica de un nacional de un tercer Estado cuyos hijos, que dependen económicamente de él, tiene la nacionalidad belga. La situación, de acuerdo con los esquemas anteriores sería puramente interna. No hay circulación, previa ni futura cierta que quede afectada por la medida. Incluso la Comisión Europea que actúa en este procedimiento como interviniente defiende que no hay vínculo con el Derecho de la Unión Europea ${ }^{20}$.

Sin embargo, en este caso parece despegar por fin del requisito del elemento transfronterizo y se fija en el disfrute efectivo de la esencia de los

15 Ibid., apartados 27 y 28.

16 Asunto C-148/02, Carlos Garcia Avello contra Bélgica, Conclusiones presentadas el 22 de mayo de 2003, Rec. 2003, p. I-11613, apartados 55 y 56.

17 Asunto C-353/06, Stefan Grunkin y Dorothee Regina Paul, Sentencia del Tribunal de Justicia de 14 de octubre de 2008, Rec. 2008, p. I-07639.

18 Ficticio o hipotético es el término utilizado por la Abogada General Sharpston en su crítica al estado actual de la jurisprudencia del Tribunal de Justicia, y que puede verse por ejemplo en sus conclusiones presentadas el 30 de septiembre de 2010, Gerardo Ruiz Zambrano contra Office national de l'emploi (ONEm), asunto C-34/09, apartado 167.

19 Asunto C-34/09, Gerardo Ruiz Zambrano contra Office national de l'emploi (ONEm), Sentencia del Tribunal de Justicia de 8 de marzo de 2011, pendiente de publicación.

20 Ibid., apartado 37. 
derechos conferidos por la ciudadanía de la Unión. No habrá libre circulación posible para los menores si tienen que acompañar a su padre fuera del territorio de la Unión.

«...el artículo 20 TFUE se opone a medidas nacionales que tengan por efecto privar a los ciudadanos de la Unión del disfrute efectivo de la esencia de los derechos conferidos por su estatuto de ciudadano de la Unión.

Pues bien, la negativa a conceder un permiso de residencia a una persona, nacional de un Estado tercero, en el Estado miembro en el que residen sus hijos de corta edad, nacionales de dicho Estado miembro, cuya manutención asume, y la negativa a concederle un permiso de trabajo, tienen tal efecto.

En efecto, debe considerarse que tal denegación del permiso de residencia tendrá como consecuencia que los mencionados menores, ciudadanos de la Unión, se verán obligados a abandonar el territorio de la Unión para acompañar a sus progenitores. [...] En tales circunstancias, estos ciudadanos de la Unión se verán, de hecho, en la imposibilidad de ejercer la esencia de los derechos que les confiere su estatuto de ciudadanos de la Unión.» ${ }^{21}$

¿Supone esta sentencia que el Tribunal de Justicia abandona la limitación de la situación puramente interna para los casos que conciernen a la ciudadanía de la Unión? Este pronunciamiento se realiza en Gran Sala, es decir, con plena consciencia de su transcendencia, y previas conclusiones por la Abogada General Sharpston ${ }^{22}$ en que se instaba directamente a un cambio jurisprudencial.

Como en otros ámbitos, el Tribunal de Justicia ha demostrado que su jurisprudencia es pendular. Ello no quiere decir que el centro de gravedad del péndulo permanezca inmóvil, pero un asunto resuelto en fecha inmediatamente posterior muestra que la jurisprudencia Ruiz Zambrano no está aún consolidada.

Se trata del asunto $M c$ Carthy $^{23}$. En el litigio, una mujer de nacionalidad británica e irlandesa contrae matrimonio con un nacional de un tercer Estado que reside ilegalmente en el Reino Unido. Esta persona pretende hacer valer su nacionalidad irlandesa - no había hecho uso de ella con anterioridad a ningún efecto - para evitar la expulsión de su cónyuge. El Tribunal de Justicia, trazando las diferencias con los asuntos Ruiz Zam-

21 Ibid., apartados 43, 43 y 44.

22 Asunto C-34/09, Gerardo Ruiz Zambrano contra Office national de l'emploi (ONEm), Conclusiones presentadas el 30 de septiembre de 2010, pendientes de publicación. En especial vid. apartados 139 y siguientes.

23 Asunto C-434/09, Shirley McCarthy contra Secretary of State for the Home Department, Sentencia del Tribunal de Justicia de 5 de mayo de 2011 pendiente de publicación. Nótese que se trata de una sentencia adoptada en Sala de cinco magistrados. 
brano $^{24}$ y García Avello ${ }^{25}$, realiza una afirmación que es aparentemente inconsistente con la conclusión que extraíamos de la anterior sentencia. Dice el Tribunal de Justicia:

«... el artículo 21 TFUE no es aplicable a un ciudadano de la Unión que nunca ha hecho uso de su derecho de libre circulación, que siempre ha residido en un Estado miembro cuya nacionalidad posee y que tiene además la nacionalidad de otro Estado miembro, siempre y cuando la situación de ese ciudadano no implique la aplicación de medidas de un Estado miembro que tengan como efecto privarle del disfrute efectivo de la esencia de los derechos conferidos por el estatuto de ciudadano de la Unión u obstaculizar el ejercicio de su derecho a circular y residir libremente en el territorio de los Estados miembros.» 26

La conclusión de todo esto es que la noción de situación puramente interna ha quedado desdibujada con la admisión de situaciones que obstaculizan el ejercicio futuro e hipotético de los derechos esenciales de la ciudadanía de la Unión, esto es, la libre circulación de personas. Pero la siguiente conclusión es que a fecha de hoy, el Tribunal de Justicia ha renunciado a superar ese límite y a abordar la cuestión directamente en términos de ciudadanía y derechos civiles, apartándose de la jurisprudencia heredada de las libertades de circulación de origen económico.

\section{La paradoja de la discriminación inversa}

Ese apartamiento no solamente dotaría de mucha más fuerza a la ciudadanía de la Unión Europea, sino que haría mucho más coherente y recubierto de seguridad jurídica al estatuto de los ciudadanos de la Unión evitando las situaciones de discriminación inversa. Estas situaciones constituyen una paradoja que mina la seguridad jurídica, como había destacado la doctrina desde hace tiempo ${ }^{27}$.

${ }^{24}$ La diferencia con este asunto se refiere a que la Sr. McCarthy no se verá obligada a salir del territorio de la Unión como consecuencia de la expulsión de su marido.

${ }^{25}$ La diferencia con este caso se refiere a que no se observa, a pesar de que existe también una doble nacionalidad, que la medida suponga graves obstáculos para el disfrute eventual futuro de la libre circulación.

${ }^{26}$ Ibid., apartado 56.

27 Vid. D'OLIVEIRA, H.U.J., «Is Reverse discrimination still permissible under the Single European Act?», en VV.AA., Forty years on : The evolution of Post-war Private International Law in Europe: symposium in celebration of the 40th anniversary of the Centre of Foreign Law and Private International Law, Kluwer Law International, Dventer, 1990; más recientemente, TRYFONIDOU, A., Reverse Discrimination in EC Law, Kluwer Law Interna- 
El paradigma de la situación de discriminación inversa se presenta en el asunto Valonia contra Flandes ${ }^{28}$. El gobierno flamenco confiere determinadas prestaciones sociales a las personas que residen en las zonas de lengua neerlandesa de Bélgica o en la región bilingüe de Bruselas. Esta medida es cuestionada tanto por el Gobierno francés como por el Gobierno valón, al entender que supone una discriminación para quienes, trabajando en esas regiones, vivían en las zonas francoparlantes de Bélgica o en Francia. El caso presentaba una solución sencilla para respecto a los residentes en Francia: constituía una barrera a la libre circulación de personas. No así para los residentes en Valonia: se trataría de una situación puramente interna.

El Tribunal de Justicia mantiene que la medida del gobierno flamenco es contraria a la libre circulación de personas en tanto en sólo cuanto se refiere a los nacionales de otros Estados miembros o a nacionales belgas que hayan ejercitado la libre circulación de personas. Admite sin embargo que para el órgano de reenvío podría ser de utilidad que considerase, en las situaciones puramente internas, la conveniencia de aplicar las mismas medidas que serían aplicables a los nacionales de terceros Estados ${ }^{29}$.

Es decir, la jurisprudencia admite esta discriminación inversa, que sabe consecuencia de sus pronunciamientos, aunque ciertamente no la desea.

No sólo la doctrina ha pedido un salto cualitativo, que ya no se puede conseguir restringiendo al máximo la noción de la situación puramente interna. Dentro del propio tribunal muy cualificadas voces, las de varios Abogados Generales ${ }^{30}$, han pedido, incluso articulado, jurídicamente este salto.

El Abogado General Poiares Maduro ha sido particularmente elocuente en este sentido. En sus conclusiones presentadas en el asunto Carbonati Apuani afirmó que:

«...A mi entender, hoy en día entre los objetivos fundamentales de la Comunidad está claramente el de evitar crear cualquier discrimina-

tional, La Haya, 2009, p. 126, en que construye una crítica a la falta de valentía del Tribunal de Justicia para enfrentarse a esta cuestión. También, SHUIBHNE, N.N., «Free Movement of Persons and the Wholly Internal Rule: Time to Move On?», en Common Market Law Review, 39(4), 2002, p. 748, y RITTER, C., «Purely internal situations, reverse discrimination, Guimont, Dzodzi and Article 234», en European Law Review, 31, 2006.

${ }^{28}$ Asunto C-212/06, Gobierno de la Communauté française y Gouvernement wallon contra Gouvernement flamand, Sentencia del Tribunal de Justicia de 1 de abril de 2008, Rec. 2008, p. I-01683.

29 Ibid., apartado 40.

${ }^{30}$ Los asuntos relativos a la ciudadanía de la Unión son una de las áreas en las que los Abogados Generales han pedido más abiertamente un cambio esencial en la jurisprudencia del Tribunal de Justicia, vid. BURROWS, N. y GREAVES, R., «The Advocates General and the concept of citizenship», en The Advocate General and EC Law, Oxford University Press, Oxford, 2007. 
ción como consecuencia de la aplicación de sus propias normas. De ello se desprende que la aplicación de una norma comunitaria debe evitar en todos los casos, en la medida de lo posible, dar lugar a una violación del principio de no discriminación.» ${ }^{31}$

Más recientemente, las conclusiones en el asunto Huber enlaza con el contenido que a su juicio debe dotarse a la ciudadanía de la Unión y sostiene:

«... La prohibición de discriminación por la razón de la nacionalidad no es ya un mero instrumento al servicio de la libertad de circulación. Constituye el núcleo central del concepto de ciudadanía europea.» ${ }^{32}$

La construcción más detallada es la que proporciona la Abogada General Sharpston en el asunto Ruiz Zambrano ${ }^{33}$. Después de razonar que la ciudadanía tiene una entidad jurídica distinta a las libertades de circulación de carácter económico, y por tanto no puede abordarse con el enfoque ortodoxo aplicado a éstas ${ }^{34}$, critica la jurisprudencia actual y propone abordar sin miramientos el problema de la discriminación inversa y la inseguridad jurídica que genera. No basta con seguir la evolución actual y llevarla a nuevas cotas:

«... es necesario evitar caer en la tentación de «estirar» el artículo 21 TFUE de manera que se extienda la protección a los que «por un escaso margen» no cumplen los requisitos. Debe existir un límite a cualquier norma que concede un derecho. Si no existe tal límite, la norma deviene indescifrable y nadie puede saber con certeza quién tendrá el derecho que confiere y quién no. Ello no va en interés de los Estados miembros o del ciudadano y socava la autoridad del Tribunal de Justicia. Por otro, si el artículo 21 TFUE se interpreta de modo demasiado restrictivo, se creará un mayor número de situaciones de discriminación inversa que tendrán que abordar los Estados miembros. Ésta tampoco parece una solución muy satisfactoria.» $^{35}$

La Abogada General mantiene que la interpretación de la cláusula de ciudadanía del artículo 18 TFUE debe hacerse en el sentido de que prohíbe

31 Asunto C-72/03, Carbonati Apuani Srl contra Comune di Carrara, Conclusiones presentadas el 6 de mayo de 2004, Rec. 2004, p. I-08027, apartado 63.

32 Asunto C-524/06 Heinz Huber contra Bundesrepublik Deutschland, Conclusiones presentadas el 3 de abril de 2008, Rec. 2008, p. I-09705, apartado 18.

33 Asunto C-34/09, Gerardo Ruiz Zambrano contra Office national de l'emploi (ONEm), Conclusiones presentadas el 30 de septiembre de 2010, pendientes de publicación.

${ }^{34}$ Ibid., apartado 131.

35 Ibid., apartado 139. 
la discriminación inversa causada por la interacción entre el artículo 21 TFUE y el Derecho nacional, al menos bajo determinadas condiciones ${ }^{36}$.

En fin, este paso no se ha dado, y sería sin duda uno de los elementos principales para verificar ese tránsito de la ciudadanía transnacional a la ciudadanía supranacional por el que abogamos. La superación de este límite, heredado de la vieja libre circulación de trabajadores, constituido por la noción de las situaciones puramente internas, ya en buena medida vaciado de contenido, permitiría superar el actual estado de artificial inseguridad jurídica y daría una eficacia más plena y homogénea a la ciudadanía de la Unión.

\section{La ciudadanía de la Unión llamada a ser un estatuto fundamental}

\section{El tradicional enfoque por categorías y los condicionantes económicos}

La evolución jurisprudencial anterior se complementa con un paralelo desprendimiento del cariz económico de la libre circulación. Ello constituye uno de los pasos, todavía hoy no completo, más importante en la elevación de la ciudadanía al rango supranacional. Para avanzar en este sentido, es preciso hablar de un estatuto único de los ciudadanos de la Unión que sea autónomo de la condición económica de ellos.

La introducción de la ciudadanía en el Tratado de Maastricht tiene este efecto formal en la libre circulación, que deja de ser de trabajadores como agentes económicos y pasa a ser de personas. Sin embargo, el enfoque por categorías se mantiene.

Las directivas comunitarias en materia de libre circulación de personas mantienen un enfoque fragmentario, manteniendo reglas distintas en función de la consideración económica de quien ejerce la libre circulación; distinguiendo así si se trata de trabajadores por cuenta ajena, por cuenta propia, parados, jubilados o estudiantes ${ }^{37}$.

36 Estas condiciones, que se desarrollan en los apartados 146, 147 y 148 de sus conclusiones, serían las siguientes: 1) el demandante debería ser un ciudadano de la Unión residente en el Estado miembro del que es nacional que no hubiera ejercido derechos de libre circulación en virtud del TFUE pero cuya situación fuera comparable, en otros aspectos materiales, a la de otros ciudadanos de la Unión en el mismo Estado miembro capaces de invocar derechos con arreglo al artículo 21 TFUE; 2) la discriminación inversa que se critica debería entrañar una infracción de un derecho fundamental protegido por el Derecho de la UE; y 3) el artículo 18 TFUE sólo se podría esgrimir como un remedio subsidiario, confinado a situaciones en las que el Derecho nacional no lleva a cabo una adecuada protección de los derechos fundamentales.

${ }^{37}$ Se trata de la Directiva 68/360/CEE del Consejo, de 15 de octubre de 1968, sobre supresión de restricciones al desplazamiento y a la estancia de los trabajadores de los Estados 
En coherencia con la normativa, el Tribunal de Justicia también siguió un enfoque por categorías.

La categoría más importante es, como es lógico, la categoría del trabajador, que el Tribunal de Justicia va expandiendo paulatinamente ${ }^{38}$. La categoría de estudiante, por ejemplo, es particularmente ejemplificadora de la ampliación del concepto de agente económico ${ }^{39}$.

La Directiva 2004/38/CE ${ }^{40}$ sobre la libertad de circulación y residencia de los ciudadanos de la Unión supera los diferentes instrumentos normativos hasta ese momento, derogando todas las directivas que daban un tratamiento parcial a estas libertades. Ahora bien, aunque introduce importantes novedades en ese sentido, no acaba del todo con el enfoque por categorías $^{41}$.

Incluso en la jurisprudencia más reciente, el Tribunal de Justicia confirma que no hay un estatuto único a la hora de abordar la libre circulación y, en particular, las prestaciones económicas y derechos sociales de acuerdo con el derecho nacional. La sentencia Föster ${ }^{42}$ es particularmente ilustrativa porque mantiene esta distinción por categorías.

La libre circulación y derecho a residencia tienen consecuencias, por la vía de la aplicación del principio de no discriminación, en la atribución de beneficios sociales a los ciudadanos de la Unión que no son nacionales. Si

miembros y de sus familias dentro de la Comunidad, la Directiva 73/148/CEE del Consejo, de 21 de mayo de 1973, relativa a la supresión de las restricciones al desplazamiento y a la estancia, dentro de la Comunidad, de los nacionales de los Estados miembros en materia de establecimiento y de prestación de servicios, la Directiva 90/364/CEE del Consejo, de 28 de junio de 1990, relativa al derecho de residencia, la Directiva 90/365/CEE del Consejo, de 28 de junio de 1990, relativa al derecho de residencia de los trabajadores por cuenta ajena o por cuenta propia que hayan dejado de ejercer su actividad profesional, y la Directiva 93/96/CEE del Consejo, de 29 de octubre de 1993, relativa al derecho de residencia de los estudiantes.

${ }^{38}$ La definición de trabajador resulta especificada en el Asunto 53/81, Levin contra Secrétaire d'État à la justice, Sentencia del Tribunal de Justicia de 23 de marzo de 1982, Rec. 1981, p. 1035, y que se va ampliando para incluir a los trabajadores a tiempo parcial, a los becarios, etc. Así en el Asunto 66/85, Lawrie-Blum, Sentencia del Tribunal de Justicia de 3 de julio de 1986, Rec. 1986, p. 2121.

${ }^{39}$ En este sentido, por ejemplo, puede citarse el Asunto 293/83, Gravier contra Liège, Sentencia del Tribunal de Justicia de 13 de febrero de 1985, Rec. 1985, p. 593.

40 Directiva 2004/38/CE del Parlamento Europeo y del Consejo, de 29 de abril de 2004, relativa al derecho de los ciudadanos de la Unión y de los miembros de sus familias a circular y residir libremente en el territorio de los Estados miembros, por la que se modifica el Reglamento (CEE) no 1612/68 y se derogan las Directivas 64/221/CEE, 68/360/CEE, 72/194/CEE, 73/148/CEE, 75/34/CEE, 75/35/CEE, 90/364/CEE, 90/365/CEE y 93/96/CEE (DO L 158 de 30 de abril de 2004).

${ }^{41}$ MOUTON, J.D., «Droit de séjour», en Rép. Communautaire Dalloz, enero 2010, p. 6.

42 Asunto C-158/07, Jacqueline Förster contra Hoofddirectie van de Informatie Beheer Groep, Sentencia del Tribunal de Justicia de 18 de noviembre de 2008 Rec. 2008, p. I-08507. 
bien es claro que este derecho corresponde igualmente a los trabajadores, no es tan claro para el resto de categorías de personas. En el asunto Bidar ${ }^{43}$, el Tribunal de Justicia señaló que, aunque los Estados miembros deban dar muestras, a la hora de organizar y aplicar el sistema de asistencia social, de cierta solidaridad económica con los nacionales de otros Estados miembros, es lícito que todo Estado miembro vele por que la concesión de ayudas destinadas a sufragar los gastos de manutención de estudiantes procedentes de otros Estados miembros no se convierta en una carga excesiva que pueda tener consecuencias para el nivel global de la ayuda que puede conceder dicho Estado.

En definitiva, no puede obviarse el enfoque económico cuando son económicas las consecuencias que se derivan del tratamiento a los ciudadanos de la Unión ${ }^{44}$. Aún así, la doctrina ha visto en el asunto Föster ${ }^{45}$ y en otra jurisprudencia los elementos necesarios para una futura igualación de los beneficios sociales a los ciudadanos de la Unión con la sola condición de la residencia ${ }^{46}$.

Pero fuera de esta materia de las ayudas sociales, cuyo análisis supera los objetivos de este estudio ${ }^{47}$, sí ha habido un progresivo avance hacia la unidad de tratamiento de la ciudadanía de la Unión.

Y la mayor manifestación sobre esta unidad de tratamiento resulta de la jurisprudencia del Tribunal de Justicia.

43 Asunto C-209/03, Bidar, Sentencia del Tribunal de Justicia de 15 de marzo de 2005, Rec. 2005, p. I-2119, en especial, apartado 56.

${ }^{44} \mathrm{Y}$ a pesar de esto, no han faltado autores que consideren que la introducción de condicionantes económicos no constituye una mera limitación tolerable de la ciudadanía de la Unión. Así, una ciudadanía de la que no pueden participar los pobres o los enfermos pone en duda la esencia o el término de «ciudadanía» según KOCHENOV, D., «Ius Tractum of many faces: European Citizenship and the difficult relationship between status and Rights», en Columbia Journal of European Law, 15, 2009, p. 169.

45 Ver en particular las conclusiones del estudio MARZO, C., «La definition d'une nouvelle méthode de jugement attachée à la citoyenneté européenne: réflexions autour de l'arrêt Förster», Revue trimestrelle de droit européen, 45(3), 2009, pp. 456-458.

46 DOUGAN, M., «Expanding the frontiers of Union Citizenship by dismantling the territorial boundaries of the national welfare States?», en BARNARD, C., y ODUDU, O. (dirs.), The outer limits of European Union Law, Hart Publishing, Oxford, 2009, pp. 116 ss.

47 Para un estudio más detallado sobre las implicaciones de la ciudadanía de la Unión en materia de derechos sociales puede consultarse el trabajo de RODIÈRE, P., «Droit social: Libre circulación de personnes et citoyenneté européenne dans la jurisprudente de la Cour de justice», Revue trimestrelle de droit européen, 42(1), 2006, pp. 165-181. Sobre los beneficios para estudiantes, puede consultarse DOUGAN, M., «Cross-border educational mobility and exportation of student financial assistance», en European Law Review, 33, 2008, pp. 723-738. 


\section{El estatuto fundamental de la ciudadanía de la Unión}

La sentencia en el asunto Grzelczyk ${ }^{48}$ es considerado como el pronunciamiento esencial en la nueva perspectiva que va a adoptar el Tribunal de Justicia. El Tribunal afirma:

«...la vocación del estatuto de ciudadano de la Unión es convertirse en el estatuto fundamental de los nacionales de los Estados miembros y permitir a aquellos de dichos ciudadanos que se encuentran en la misma situación obtener, independientemente de su nacionalidad y sin perjuicio de las excepciones expresamente previstas a este respecto, el mismo trato jurídico.» ${ }^{49}$

En el asunto Baumbast ${ }^{50}$ se plasma esta perspectiva de la siguiente forma:

«... se ha introducido el estatuto de ciudadano de la Unión en el Tratado $\mathrm{CE}$ y [...] el artículo $18 \mathrm{CE}$, apartado 1 , ha reconocido a todo ciudadano el derecho a circular y residir libremente en el territorio de los Estados miembros. En virtud del artículo $17 \mathrm{CE}$, apartado 1, será ciudadano de la Unión toda persona que ostente la nacionalidad de un Estado miembro. La vocación del estatuto de ciudadano de la Unión es convertirse en el estatuto fundamental de los nacionales de los Estados miembros.» ${ }^{51}$

Es decir, que el Tribunal de Justicia ha puesto los cimientos con estos pronunciamientos, que después se han reiterado en su jurisprudencia posterior $^{52}$, para que el estatuto de la ciudadanía sea único.

A ello ha contribuido también el legislador europeo con la Directiva 2004/38, al introducir conceptos como la residencia permanente, que ya opera sin limitación alguna de tipo económico. La doctrina ha razonado que este instrumento ha contribuido al salto de la libertad de circulación a

48 Asunto C-184/99, Rudy Grzelczyk contra Centre public d'aide sociale d'Ottignies-Louvain-la-Neuve, Sentencia del Tribunal de Justicia de 20 de septiembre de 2001, Rec. 2001, p. I-06193.

49 Ibid., apartado 31.

50 Asunto C-413/99, Baumbast contra Secretary of State for the Home Department, Sentencia del Tribunal de Justicia de 17 de septiembre de 2002, Rec. 2002, p. I-07091.

51 Ibid., apartados 81 y 82.

52 Asuntos C-224/98, D’Hoop, Sentencia del Tribunal de Justicia de 11 de julio de 2002, Rec. 2002, p. I-6191apartado 28; asunto C-544/07, Rüffler, Sentencia del Tribunal de Justicia de 23 de abril de 2009, Rec. 2009, p. I-3389, apartado 62; asunto C-503/09, Steward, Sentencia del Tribunal de Justicia de 21 de julio de 2011, pendiente de publicación, apartado 80. 
la configuración de un derecho fundamental del que se pretenden omitir las condiciones económicas ${ }^{53}$.

Por tanto, en este aspecto también, estamos ante un inminente salto hacia una configuración única de la ciudadanía de la Unión desprovista de categorías marcadas por condicionantes de tipo económico.

\section{El nacimiento de derechos políticos supranacionales}

\section{Los derechos de sufragio activo y pasivo: derechos puramente transnacionales}

Uno de los aspectos más revolucionarios de la ciudadanía introducida en el Tratado de Maastricht era la inclusión de derechos políticos. Estos derechos se concretaban en el derecho de sufragio activo y pasivo de todo ciudadano comunitario en las elecciones locales y al Parlamento Europeo.

Fue revolucionario en su momento porque buena parte de los Estados miembros debieron modificar sus normas constitucionales para dar acogida a esta previsión, como fue el caso de España ${ }^{54}$, o bien a acogerlas con ciertas limitaciones, como fue el caso de Francia ${ }^{55}$. Pero además de que las Directivas ${ }^{56}$ que han desarrollado las normas básicas del ejercicio de estos derechos no hayan fijado un procedimiento electoral uniforme, lo cual hubiera sido esperable en las elecciones al Parlamento Europeo, lo relevante a los efectos del análisis que estamos realizando es que se trata de derechos políticos transnacionales.

Es decir, son derechos que tienen sentido sólo cuando existe una libre circulación, son derechos que se garantizan a los ciudadanos de la Unión cuando residen en un país que no es el de su nacionalidad.

53 PLIAKOS, A., «Citoyenneté», en Rép. Communautaire Dalloz, agosto 2005, p. 8.

${ }^{54}$ Artículo 13.2 de la Constitución española modificado por la reforma constitucional de 27 de agosto de 1992

55 En Francia, el Consejo constitucional juzgó que, aunque las elecciones municipales no entrañaban poderes esenciales a la soberanía nacional, sí podía hacerlo la elección como alcaldes de ciudadanos europeos no franceses, ya que los alcaldes tienen en Francia un derecho cualificado de voto en el Senado. Vid. decisión

56 Son la Directiva 93/109/CE del Consejo, de 6 de diciembre de 1993, por la que se establecen las modalidades del ejercicio del derecho de sufragio activo y pasivo en las elecciones al Parlamento Europeo para los ciudadanos de la Unión que residan en un Estado miembro del que no son nacionales; y la Directiva 94/80/CE del Consejo, de 19 de diciembre de 1994, por la que se fijan las modalidades de ejercicio del derecho de sufragio activo y pasivo en las elecciones municipales por parte de los ciudadanos de la Unión residentes en un Estado miembro del que no sean nacionales. 
Las condiciones para el ejercicio de estos derechos de voto se fundan en el principio de no discriminación. El Tribunal de Justicia ha renunciado a fijar un límite a que sean sólo los ciudadanos de la Unión quienes tengan estos derechos. En el asunto España contra el Reino Unido ${ }^{57}$, a cuenta de la ampliación del derecho de voto en el Parlamento Europeo a los residentes en Gibraltar con ciudadanía de la Commonwealth, esto es, distintos de los nacionales británicos, el Tribunal de Justicia estima que esta ampliación del derecho de voto a nacionales de terceros Estados es legítima.

Sin embargo, lo que el Tribunal no admite es que se limite este derecho de voto a los nacionales del propio Estado. Así lo manifestó en el asunto Eman y Sevinger ${ }^{58}$, de la misma fecha que la anterior sentencia, respectos de los ciudadanos neerlandeses residentes en el territorio de Aruba.

Aunque este último pronunciamiento supone la fijación de una regla sobre las leyes del Estado que afectan a los derechos políticos de sus propios nacionales, la conclusión que cabe sacar de estos derechos permanece inmutable: se trata de derechos de ciudadanía transnacional, no supranacional.

Teniendo en cuenta que el porcentaje de la población europea que hace uso efectivo de la libertad de circulación en la Unión es muy reducido, difícilmente puede estos derechos políticos transnacionales facilitar la formación de un sentimiento de pertenencia común.

\section{Los derechos de petición, de recurrir al Defensor de Pueblo y de} dirigirse a las Instituciones: derechos no exclusivos de los ciudadanos

¿Podemos ver en los demás derechos políticos vinculados al estatuto de la ciudadanía un carácter supranacional? Procede analizar los derechos enumerados en el artículo 20.2.d) TFUE, es decir, los derechos de formular peticiones al Parlamento Europeo, de recurrir al Defensor del Pueblo Europeo, así como de dirigirse a las instituciones y a los órganos consultivos de la Unión en una de las lenguas de los Tratados y de recibir una contestación en esa misma lengua.

Aunque no son derechos de participación política en sentido estricto, sí son supranacionales en el sentido en que se confieren directamente a los

57 Asunto C-145/04, Reino de España contra Reino Unido de Gran Bretaña y de Irlanda del Norte, Sentencia del Tribunal de Justicia de 12 de septiembre de 2006, Rec. 2006, p. I-07917.

58 Asunto C-300/04, M.G. Eman y O.B. Sevinger contra College van burgemeester en wethouders van Den Haag, Sentencia del Tribunal de Justicia de 12 de septiembre de 2006, Rec. 2006, p. I-08055. 
ciudadanos de la Unión sin que sea necesario un elemento transfronterizo. El problema para erigirlos en derechos civiles de la ciudadanía es que, en realidad, no son derechos exclusivos de los ciudadanos sino que corresponden a todos los residentes legales en el territorio de la Unión, así como a las personas jurídicas. En efecto, los artículos 227 y 228 TFUE hablan de los ciudadanos de la Unión Europea, así como de cualquier persona física o jurídica que resida o tenga su domicilio social en un Estado miembro.

\section{La iniciativa ciudadana europea}

El Tratado de Lisboa introduce una novedad fundamental y revolucionaria en el plano de los derechos de participación política. Heredero del Tratado Constitucional, el Tratado de la Unión Europea establece el derecho de la iniciativa ciudadana. Según el artículo 11.4 TUE:

«Un grupo de al menos un millón de ciudadanos de la Unión, que sean nacionales de un número significativo de Estados miembros, podrá tomar la iniciativa de invitar a la Comisión Europea, en el marco de sus atribuciones, a que presente una propuesta adecuada sobre cuestiones que estos ciudadanos estimen que requieren un acto jurídico de la Unión para los fines de la aplicación de los Tratados.»

Este derecho ha sido desarrollado, como ordenaba el artículo 24.1 TFUE, por el Reglamento 211/2011, sobre la iniciativa ciudadana europea ${ }^{59}$. Éste es un derecho de participación política verdaderamente supranacional, concedido por los Tratados a los ciudadanos de la Unión sin vinculación a un movimiento transfronterizo. La doctrina de la ciencia política especializada ha considerado que este derecho tiene un potencial político sin precedentes ${ }^{60}$.

El ejercicio de este derecho requiere una participación mínima en al menos siete Estados miembros, de forma que se garantice que la iniciativa no responde a una sensibilidad puramente nacional.

Sin embargo, desde una perspectiva jurídica la iniciativa ciudadana europea tiene una importante limitación de que carecen otros sistemas nacio-

59 Reglamento (UE) n. ${ }^{\circ}$ 211/2011 del Parlamento Europeo y del Consejo, de 16 de febrero de 2011, sobre la Iniciativa Ciudadana Europea, publicada en el DOUE, serie L 64 de 11 de marzo de 2011.

60 WARLEIGH, A., «On the path to legitimacy? A critical deliberativist perspective on the right to the citizens“ initiative», en RUZZA y DELLA SALA (eds.), Governance and civil society in the European Union: Normative perspectives (vol. 1), Manchester University Press, Manchester, 2007, p. 64. 
nales en los que se ha regulado este instrumento ${ }^{61}$, y que consiste en que la iniciativa no se dirige directamente al legislador, sino que pasa previamente por la Comisión. El especial equilibrio institucional en el proceso legislativo europeo hacía que una solución sin contar con la Comisión hubiera sido demasiado perturbadora. La Comisión verificará que se ha respetado la regularidad del proceso de recogida de firmas, para lo que se valdrá de la colaboración de los Estados miembros. Pero además, la Comisión puede no tramitar la iniciativa, y no elevarla al Parlamento Europeo y el Consejo, por razones tanto jurídicas como políticas o de conveniencia. Esta decisión, que deberá ser motivada, entra dentro de la discrecionalidad política de la Comisión y, por tanto, no es en principio susceptible de recurso jurisdiccio$\mathrm{nal}^{62}$.

Ello ciertamente puede limitar la efectividad de este derecho, pero no es menos cierto que la Comisión deberá, dar buenas razones para no dar trámite a una iniciativa democrática ciudadana, ya que en caso contrario su actuación sería cuestionable en términos políticos.

Dado lo reciente de la regulación, la iniciativa ciudadana europea no se ha hecho efectiva en la práctica. Sin embargo, la organización Greenpeace, antes de la entrada en vigor del Reglamento introdujo una iniciativa, refrendada por más de un millón de ciudadanos, en un área de regulación notoriamente controvertida como es la autorización del comercio alimentario con organismos modificados genéticamente. La Comisión la tramitó como un ejercicio del derecho de petición ${ }^{63}$, aunque en varios medios de comunicación quedó reflejado como la primera iniciativa ciudadana europea.

El Reglamento 211/2011 comienza a ser aplicable a partir del 1 de abril de 2012, según su artículo 23.2. Aunque a la fecha de redacción de este estudio no hay todavía iniciativas registradas en la página web de la Comisión $^{64}$, existen ya varias plataformas ${ }^{65}$, fundamentalmente a través de Internet que es uno de los medios expresamente previstos en el Reglamento, que

${ }^{61}$ Es el caso de Austria, Eslovenia, España, Hungría, Italia, Letonia, Lituania, Polonia y Portugal.

62 Vid. más sobre esta cuestión en SZELIGOWSKA, D. y MINCHEVA, E., «A European Citizens' Initiative: Empowering European citizens within the institucional triangle: A political and legal analysis», en Bruges Political Research Papers, 24 , 2012, p. 71.

${ }_{63}$ Extracto de prensa, MEMO/10/683, disponible en http://europa.eu/rapid/pressReleasesAction.do?reference=MEMO/10/683\&type=HTML, consultado por última vez en fecha 10/4/2012. 2012).

${ }^{64} \mathrm{http} / / /$ ec.europa.eu/citizens-initiative/public/welcome (última consulta el 10 de abril de

65 Desde la página web http://www.citizens-initiative.eu/ (última consulta el 10 de abril de 2012), pueden consultarse una relación informal de las iniciativas que se hallan en una fase embrionaria. 
han comenzado campañas de recogida de firmas. Estas campañas, aún no registradas oficialmente, versan, entre otros asuntos, sobre: una mayor integración europea a través de un único sistema fiscal y presupuestario (iniciativa «Eurofederation») ${ }^{66}$; el matrimonio entre personas del mismo sexo $^{67}$; la fijación de una renta básica garantizada ${ }^{68}$; la supresión de la energía nuclear $^{69}$; el reconocimiento de un derecho fundamental a la nacionalidad del Estado miembro_donde se reside ${ }^{70}$; la protección del agua cuyo acceso debe ser un derecho ${ }^{71}$; o la protección de la independencia y el pluralismo de los medios de comunicación ${ }^{72}$.

La sensibilidad política de la Comisión, así como de las demás Instituciones, determinará en buena medida el éxito del ejercicio de este derecho en la práctica. Pero también será esencial la eficacia de las organizaciones que organicen recogida de firmas en asuntos cuya relevancia política vaya más allá de un solo Estado miembro.

\section{Ciudadanía de la Unión y nacionalidad de los Estados miembros: ¿relación en una sola dirección?}

\section{El derecho de la nacionalidad: competencia soberana de los Estados miembros}

La relación entre la ciudadanía de la Unión y la nacionalidad de los Estados miembros ha venido marcada por la unilateralidad. La nacionalidad de los Estados miembros es una conditio sine qua non de la ciudadanía de la UE, pero ésta no debe influir en modo algo en la segunda.

Así queda subrayado en los Tratados. El artículo 9 del Tratado de la Unión Europea, de idéntico tenor que el artículo 20.1 del Tratado de Funcionamiento de la Unión Europea, proclama:

«Será ciudadano de la Unión toda persona que tenga la nacionalidad de un Estado miembro. La ciudadanía de la Unión se añade a la ciudadanía nacional sin sustituirla.»

\footnotetext{
66 http://www.eurofederation.eu/

${ }^{67} \mathrm{https} / / / \mathrm{www} \cdot$ peticiongay.com/

$68 \mathrm{http}: / /$ binews.org/2011/12/opinion-european-citizens-initiative-concerning-unconditional-basic-income/

$69 \mathrm{http} / / /$ www.global2000.at/

$70 \mathrm{http} / / / \mathrm{www}$. letmevote.eu/

${ }^{71} \mathrm{http}: / / \mathrm{www}$. right2 water.eu/

$72 \mathrm{http} / /$ www.euroalter.com/2011/launching-a-european-citizens-initiative-for-mediapluralism/
} 
Este último inciso, quizá por ser innecesario, pone de manifiesto precisamente el temor de los Estados a que la ciudadanía influya en la normativa interna sobre la nacionalidad y fue introducido en el Tratado de Ámsterdam ${ }^{73}$, ya que no existía esa mención en la versión originaria del Tratado de la Unión Europea de Maastricht.

Se pretende por tanto que las disposiciones sobre ciudadanía no afecten a las competencias soberanas de los Estados para determinar quienes son sus súbditos y bajo qué condiciones ejercen la nacionalidad. Pero el esquema, aparentemente simple por el cual la ciudadanía de la Unión se añade, simplemente, a la nacionalidad de los Estados miembros de la Unión es insuficiente. La ciudadanía de la Unión puede ser capaz, como ha mantenido algún autor ${ }^{74}$, de subvertir las premisas fundamentales y la lógica del Derecho de la nacionalidad.

Lo que ocurre es que la fuerza expansiva de la ciudadanía va a ser capaz de influir, en la medida que veremos a continuación, en las legislaciones de los Estados miembros sobre la nacionalidad. No puede pasarse por alto que la plena soberanía de los Estados miembros para acordar la nacionalidad y fijar su eficacia no puede ser libérrima cuando las normas de otros Estados miembros, esencialmente distintas, entran en colisión y dan lugar a situaciones de incoherencia que el Tribunal de Justicia ha debido ordenar.

Como punto de partida conviene resaltar que el Derecho de la nacionalidad es una de las mayores manifestaciones de la identidad nacional de los Estados y constituye un parte esencial de su soberanía. Ahora bien, conocido este presupuesto, no puede obviarse que esta facultad no puede ser ilimitada porque afecta a otros Estados, incluso a principios generales del Derecho Internacional Público.

Fuera de la jurisdicción de la Unión Europea, el asunto Nottebohm ${ }^{75}$, ventilado ante el Tribunal Internacional de Justicia de La Haya, merece ser mencionado. Este caso versa sobre la concesión de una nacionalidad de Liechtenstein de un nativo alemán, con ninguna relación con el pequeño país alpino, y que pretendía hacer valer esta nacionalidad frente a Guatemala, que le había arrestado en su condición de nacional de un país enemigo (Alemania durante la II Guerra Mundial). El Tribunal se pronuncia

${ }^{73}$ En realidad, el inciso que se incluye en el Tratado de Amsterdam, y que se mantiene en la versión del Tratado de Niza, es la siguiente: «La ciudadanía de la Unión será complementaria y no sustitutiva de la ciudadanía nacional.»

${ }^{74}$ Es interesante el desarrollo la tesis que se apunta en el estudio de KOSTAKOPOULOU, D., «European Union citizenship: writing the future», en European Law Review, 13(5), 2007, pp. 623-646.

75 Asunto Nottebohm, Sentencia del Tribunal Internacional de Justicia de 6 de abril de 1955, , Recopilación del Tribunal Internacional de Justicia de 1955, p. 5. 
en contra de obligar a Guatemala a reconocer como válida la naturalización acordada por Liechtenstein, porque se trataría de una mera nacionalidad de conveniencia.

El Tribunal de Justicia de la Unión Europea nunca se ha pronunciado en sentido de restringir el derecho a conceder la nacionalidad por los Estados miembros. Más bien al contrario, ha señalado que es a éstos a quienes corresponde fijar estas normas, tanto relativas a la adquisición de la nacionalidad como a su ejercicio.

Así lo manifiesta por ejemplo en el asunto $\mathrm{Kaur}^{76}$, relativo a la validez de la modificación de las normas británicas de la nacionalidad en lo que concernía a los ciudadanos de la Commonwealth. El Tribunal de Justicia manifiesta que:

«la determinación de los modos de adquisición y pérdida de la nacionalidad es, de conformidad con el Derecho internacional, competencia de cada Estado miembro, $[\ldots]$ sobre la base de dicho principio de Derecho consuetudinario internacional, atendido su pasado imperial y colonial, el Reino Unido ha establecido varias categorías de ciudadanos británicos a los que ha reconocido distintos derechos en función de la naturaleza de los vínculos que los unían con el Reino Unido.» ${ }^{77}$

Esta jurisprudencia se repite en otros casos, como Mesbah ${ }^{78}$, garantizando el respeto a la competencia nacional.

Pero el respeto a las normas internas de la nacionalidad implica para los Estados miembros limitaciones que se derivan precisamente de la necesidad de reconocer esta facultad en los demás.

Esta circunstancia cobra especialmente relevancia en los casos de doble nacionalidad. En el asunto Micheletti ${ }^{79}$, el Tribunal de Justicia consideró que España debía reconocer titular de las libertades comunitarias a una persona con doble nacionalidad argentina e italiana. Ello aunque se contrariara la norma española del Código Civil ${ }^{80}$ que determina que en caso de doble nacionalidad debe prevalecer, siempre que una de ellas no sea la nacionalidad española, la nacionalidad de la residencia, que en este caso era argentina.

76 Asunto C-192/99, Manjit Kaur, Sentencia del Tribunal de Justicia de 20 de febrero de 2001, Rec. 2001, p. I-01237.

77 Ibíd. apartados 19 y 20.

78 Asunto C-179/98, Bélgica contra Fatna Mesbah, Sentencia del Tribunal de Justicia de 11 de noviembre de 1999, Rec. 1999, p. I-07955.

79 Asunto C-369/90, Mario Vicente Micheletti contra Delegación del Gobierno en Cantabria, Sentencia del Tribunal de Justicia de 7 de julio de 1992, Rec. 1992, p. I-04239.

${ }^{80}$ Artículo 9.9 del Código Civil. 
El razonamiento del respeto a la nacionalidad concedida por otro Estado aparece en otros casos, como el asunto Zhu y $\mathrm{Chen}^{81}$, en que se afirma que el Reino Unido debe reconocer como ciudadanos de la Unión a las personas nacidas en Irlanda del Norte, dado que la República de Irlanda les confiere su nacionalidad. También en el asunto García Avello, antes examinado, aporta una perspectiva similar, aunque aquí sin que haya existido libre circulación.

Hasta aquí observamos que no hay sino un respeto escrupuloso a las normas nacionales, resolviendo los conflictos generados por los casos en que unas y otras normas entran en colisión.

\section{El Derecho de la nacionalidad debe encuadrarse en el Derecho de la Unión}

Pero, ¿hay algo más que introduzca la ciudadanía de la Unión? Pues bien, el Tribunal de Justicia va a reconocer que sí puede el Derecho de la Unión, a través de la ciudadanía, afectar al Derecho interno de la nacionalidad.

El asunto Rottmann ${ }^{82}$ representa el pronunciamiento clave sobre esta cuestión. El asunto se refiere a un nacional austriaco que fija su residencia en Alemania. Siendo investigado por un delito en Austria, se dicta una orden de detención contra el mismo pero, poco después, se naturaliza como alemán, sin mencionar los hechos delictivos por los que es investigado. La Ley austriaca determina la pérdida de su nacionalidad por la adquisición de otra y, a la vez, la Ley alemana determina la pérdida, con efectos retroactivos, de la nacionalidad adquirida, como sanción a la omisión de datos en el procedimiento de naturalización. Por ello, una vez conocidas estas circunstancias, el interesado pierde la nacionalidad alemana sin recuperar la austriaca.

Como consecuencia de este cúmulo de sucesos, unido a la aplicación de normas sobre la adquisición y pérdida de la nacionalidad que no han sido necesariamente pensadas para un funcionamiento armónico con el resto de leyes de los Estados miembros, se produce un evento que afecta a la esencia de la ciudadanía de la Unión. El señor Rottmann perdería la ciudadanía de la UE, de forma no voluntaria, así como la libre circulación en el territorio

${ }^{81}$ Asunto C-200/02, Kunqian Catherine Zhu y Man Lavette Chen contra Secretary of State for the Home Department, Sentencia del Tribunal de Justicia de 19 de octubre de 2004, Rec. 2004, p. I-09925.

82 Asunto C-135/08, Janko Rottman contra Freistaat Bayern, Sentencia del Tribunal de Justicia de 2 de marzo de 2010, Rec. 2010, p. I-01449. 
de la Unión y el resto de derechos que conlleva. El Tribunal de Justicia no puede aceptar sin más este resultado invocando la exclusión de su jurisdicción de las normas estatales sobre la nacionalidad.

Aunque el Tribunal de Justicia no se pronuncia directamente sobre una obligación de Austria de reponer a la persona en su nacionalidad austriaca, ya que la decisión sobre si se iba a hacer no se había tomado todavía, sí interesa destacar el pronunciamiento siguiente:

«es preciso recordar que los principios derivados de la presente sentencia en cuanto a la competencia de los Estados miembros en materia de nacionalidad así como su obligación de ejercer esta competencia respetando el Derecho de la Unión se aplican tanto al Estado miembro de naturalización como al Estado miembro de la nacionalidad de origen.» ${ }^{83}$

La competencia, que es indubitadamente nacional, sobre la adquisición y pérdida de la nacionalidad debe ejercitarse respetando el Derecho de la Unión y, en particular, con sus disposiciones en materia de ciudadanía. La competencia estatal, en definitiva, se enmarca en el Derecho de la Unión.

El respeto a las normas básicas del Derecho comunitario, incluso por la normativa interna de adquisición de la nacionalidad, ya había sido reconocida como imperativa por el Tribunal de Justicia mucho antes de que las disposiciones sobre la ciudadanía aparecieran en los Tratados, como ocurrió en el asunto Airola ${ }^{84}$. El Tribunal de Justicia se decidió no tener en cuenta, a efectos de la aplicación del Estatuto de los Funcionarios, la naturalización italiana de una funcionaria de nacionalidad belga, basándose en que dicha naturalización le había sido impuesta, de conformidad con lo dispuesto en el Derecho italiano, sin posibilidad de renunciar a ella, a raíz de su matrimonio con un italiano, vulnerando el principio comunitario de igualdad de trato entre funcionarios masculinos y femeninos.

Lo que ocurre es que las normas y principios de la ciudadanía tienen una fuerza expansiva y una conexión con la nacionalidad que llevan a que esta posible influencia sea mucho mayor en el futuro.

\section{Conclusiones}

La mirada a los cuatro aspectos de la ciudadanía de la Unión que hemos trazado en este estudio nos lleva a la conclusión de que estamos en un mo-

${ }^{83}$ Ibid. apartado 62.

${ }^{84}$ Asunto 21/74, Airola contra Comisión, Sentencia del Tribunal de Justicia de 20 de febrero de 1975, Rec. 1975, p. 221. 
mento, en un estadio jurisprudencial, que ha sentado los fundamentos para un inminente tránsito de una concepción clásica - transnacional y con un cariz económico - de la ciudadanía de la Unión a una concepción nueva, supranacional y como estatuto único.

La jurisprudencia del Tribunal de Justicia ha ido poniendo, muy especialmente en los pronunciamientos más recientes, los fundamentos que marcarán este tránsito.

El carácter transfronterizo de la ciudadanía, marcado por la herencia de la libre circulación, difumina sus contornos hasta prácticamente desaparecer. La limitación que entraña la noción de las situaciones puramente internas queda reducida a su mínima expresión, bajo los razonamientos en términos hipotéticos del Tribunal de Justicia.

La ciudadanía va ganando la condición de estatuto fundamental de los ciudadanos de la Unión, marginando al enfoque fragmentario según categorías, aunque se mantienen las incógnitas respecto a los derechos del Estado del bienestar que por el momento no se pueden hacer depender de la condición, no discriminatoria, de la mera residencia. Esa vocación de estatuto fundamental de la que habla la jurisprudencia nos lleva a una consideración de derecho civil y político per se, alejado de los condicionantes económicos y transfronterizos de antaño.

Mientras tanto, el Tribunal de Justicia se rinde a la evidencia de que la nacionalidad, competencia soberana de los Estados, no puede mantenerse absolutamente indemne a la fuerza expansiva de la ciudadanía de la Unión.

En realidad, esta construcción de una ciudadanía más fuerte pasa no sólo por un reconocimiento de derechos autónomos de circulación o de condiciones económicas, sino de la configuración de un cierto «pueblo europeo» con una relación de lealtad a no sólo a la Unión y al Estado miembro de que son nacionales, sino también a los demás Estados miembros.

Recientemente, el Abogado General Cruz Villalón se expresaba a través de unas conclusiones ${ }^{85}$ de forma particularmente elocuente sobre este punto:

«la noción de lealtad, como manifestación de compromiso y solidaridad con la comunidad política, no puede considerarse ya signo distintivo, exclusivo y excluyente, de los Estados miembros en tanto que tales, de tal modo que requiera ineluctablemente del vínculo de la nacionalidad. Al

85 Asuntos acumulados C-47/08, C-50/08, C-51/08, C-53/08, C-54/08 y C-61/08, Comisión / Reino de Bélgica, República Francesa, Gran Ducado de Luxemburgo, República de Austria, República Federal de Alemania, República Helénica, Conclusiones presentadas el 14 de septiembre de 2010, pendiente de publicación, apartado 142. Este asunto se refiere a la declaración de incumplimiento de varios Estados miembros que mantienen el requisito de la nacionalidad para el acceso a la profesión de notario. 
contrario, el ciudadano europeo, en tanto que tal, no es ajeno a un compromiso de lealtad con la Unión. Una premisa con arreglo a la cual un nacional de un Estado miembro no encontraría modo de expresar un legítimo compromiso de lealtad con otro Estado miembro si no es previa adopción de la nacionalidad correspondiente a este último, supondría un cuestionamiento notable tanto de los artículos 17 y $18 \mathrm{CE}$, como de los derechos políticos de ciudadanía derivados de los Tratados, al igual que de la Carta de los Derechos Fundamentales de la Unión Europea.»

A la vez, aparece un derecho político nuevo y verdaderamente supranacional; la iniciativa ciudadana europea. Quizá la eficacia de este derecho sea aún poco más que simbólica, pero contribuye facilitar la participación activa de los ciudadanos europeos en la Unión, en definitiva, a configurar una comunidad política común.

La ciudadanía de la Unión se configura así, poco a poco, como el vínculo, con efectos jurídicos diversos, entre los ciudadanos y la Unión, desbordando el marco del Mercado Interior y sin necesidad de que exista un elemento transfronterizo. 